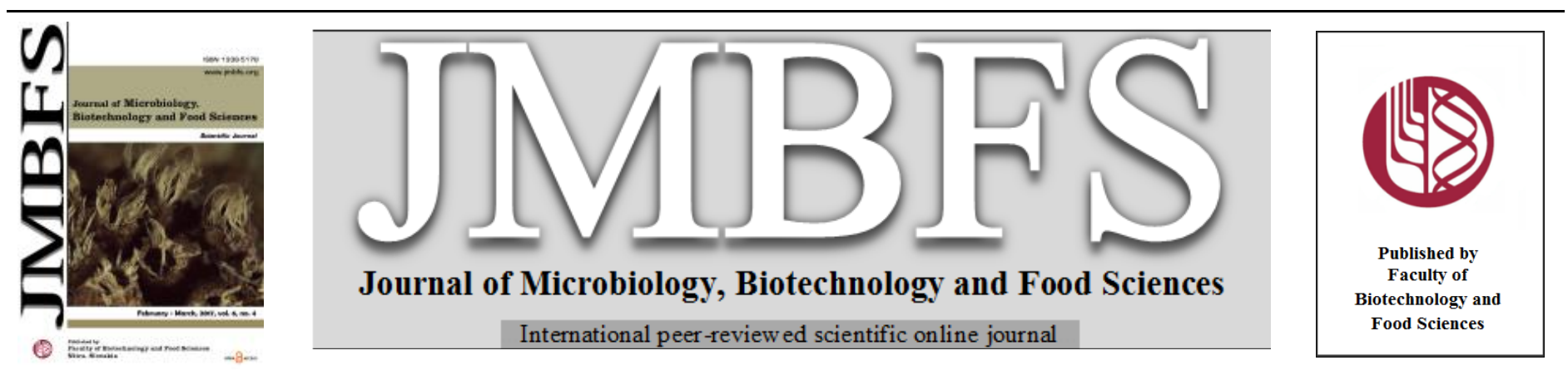

\title{
THE IN VITRO EFFECTS OF SILVER NANOPARTICLES ON BACTERIAL BIOFILMS
}

\author{
Reza Ghotaslou ${ }^{1,2 *}$, Zahra Bahari ${ }^{3}$, Abdullah Aliloo ${ }^{1,2}$, Pourya Gholizadeh ${ }^{2}$, Behnaz Salahi Eshlaghi ${ }^{4}$ \\ $\operatorname{Address}(e s)$ : \\ ${ }^{1}$ The Endocrine Research Center, Tabriz University of Medical Sciences, Tabriz, Iran. \\ ${ }^{2}$ Department of Microbiology, School of Medicine, Tabriz University of Medical Sciences, Tabriz, Iran. \\ ${ }^{3}$ Rab-e -Rashidi University, Tabriz, Iran. \\ ${ }^{4}$ Research Center of Midwife School, Tabriz University of Medical Sciences ,Tabriz, Iran.
}

*Corresponding author: rzgottaslo@yahoo.com

doi: 10.15414/jmbfs.2017.6.4.1077-1080

\section{ARTICLE INFO}

Received 21. 9. 2015

Revised 22. 12. 2015

Accepted 13. 12. 2016

Published 1. 2. 2017

Regular article

open 2 access

\begin{abstract}
Biofilm formation is one of the most important bacterial virulence factors that plays a key role in infections. In the present study, effects of silver nanoparticles were evaluated in vitro against bacterial biofilm. Ninety bacterial isolates were selected for study. The Congo Red agar, tube and microtitre assays were used for the detection of biofilm. Antimicrobial effects of silver nanoparticles were determined by the Kirby-Bauer and microdilution methods. The microtitre assay was used to study the biofilm inhibition activity. The most common biofilm producing bacteria was Staphylococcus aureus. The power of biofilm production is different among bacteria, and the effect of silver nanoparticles against Escherichia coli was less than Staphylococcus aureus and Pseudomonas aeruginosa. The silver nanoparticles are effective against planctonic and biofilm forms. Because of the importance of biofilm in infectious diseases and the development of drug resistance, silver nanoparticles may be an appropriate way for the control and the prevention of biofilm.
\end{abstract}

Keywords: Bacteria, Biofilm, Silver nanoparticles

\section{INTRODUCTION}

Biofilms are complex and organized communities of bacteria that grow on animate and inanimate surfaces (Høiby et al., 2014; Southey-Pillig et al.,2005). Biofilm formation is one of the most important bacterial virulence factors that play a key role in serious infections (Hassan et al., 2011; Joseph, 2003; Odeyemi et al., 2012). Microbial biofilms can cause skin, wound and teeth infections, are a serious risk factor for patients using artificial biomedical devices such as contact lenses, central venous catheters, urinary catheters, artificial heart valves and intrauterine devices, and can cause serious problems in immune-compromised hosts (Czaczyk and Myszka, 2007; Mah and O`Toole, 2001). It is estimated that about $65 \%$ of human infections are related to the biofilm (Mah and O`Toole, 2001).

Considering the importance of biofilm in infectious diseases and increasing drug resistance, scientists are searching for appropriate ways to control and preven biofilm. In general, therapy with a combination of antibiotics, novel cephalosporin, metals chelating agents, quorum sensing inhibitors, halogens, phage therapy and nanoparticles are used as antibiofilm agents (Czaczyk and Myszka, 2007). The diameter of the nanoparticles is about 1 to $100 \mathrm{~nm}$ and possess sole physicochemical, optical and biological properties (Whitesides, 2003). Nanoparticles have wide applications in the medical field, including targeted drug delivery, imaging, artificial implants and are also included in the antimicrobial performance to destroy the wide range of pathogens and drug resistant organisms (Samia et al., 2006). Numerous natural and engineered nanoparticles which have strong antimicrobial properties are silver, gold, magnesium, zinc, copper, aluminum, platinum, palladium, and titanium (Ravishankar and Jamuna, 2011). Silver is a metallic element about the atomic number 47 and silver compounds are used in the treatment of wounds, burns and infectious diseases (Dunn and Edvards-Jones., 2004). Silver nanoparticles have been used as a medium to delivery antibiotics and synthetic compounds used in antiseptic filters and coating materials (Kim et al., 2007). The objective of our study was to determine in vitro effects of silver nanoparticles against bacterial biofilms.

\section{MATERIALS AND METHODS}

\section{Identification and biofilm detection}

Bacteria were isolated from various samples including ulcer, throat, mucus and urine, and were identified by standard tests (Mahon, 2014). Ninety bacteria isolates were selected which included Staphylococcus aureus $(S$. aureus $)(\mathrm{n}=30)$, Escherichia coli $($ E.coli) $(\mathrm{n}=30)$ and Pseudomonas aeruginosa (P. aeruginosa) $(\mathrm{n}=30)$. In this study, we used three methods for the detection of biofilm-forming isolates including Congo red agar(CRA), tube method (TM) and microtitre assay (MA) (Hassan et al,2011).

\section{Congo- Red Agar method}

Biofilm production was evaluated using cultivation isolates on Congo Red Agar (CRA), comprising $0.8 \mathrm{~g}$ of Congo red (Sigma, the USA) and $36 \mathrm{~g}$ of saccharose (Sigma, the USA) to one litter of brain heart infusion agar (Merck, Germany). Inoculated CRA dishes were incubated at $37 \mathrm{o}^{\circ} \mathrm{C}$ for $24 \mathrm{~h}$ followed by storage at room temperature for $48 \mathrm{~h}$. The production of rough black colonies by biofilm producing isolates was used to distinguish them from non-biofilm producing strains.

\section{Tube method}

Overnight fresh culture of bacterial isolates (equal to $1 \mathrm{McFarland}$ ) was prepared; $100 \mu \mathrm{L}$ of this suspension was inoculated into $3 \mathrm{~mL}$ of Trypticase Soy Broth (Merck, Germany) with 2\% glucose (Sigma, the USA) in a glass test tube. After overnight incubation at $37{ }^{\circ} \mathrm{C}$, the test tube was decanted and washed 3 times with

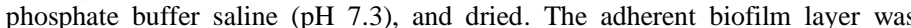
stained with crystal violet $0.1 \%$ for $20 \mathrm{~min}$, and the excess stain was washed with deionized water. The tubes were dried in an inverted position. The strains which showed an adherent and visible biofilm layer on internal walls of the test tubes were considered as positive. 


\section{Synthesis of silver nanoparticles}

Chemical reduction method was used for synthesis of silver nanoparticles by Sodium Boron hydride $\left(\mathrm{NaBH}_{4}\right)$. To stabilize the solution, $0.3 \%$ polyvinyl pyrolidine (PVP) was added to the solution to prevent the particles density. The size of nanoparticles in the silver nanoparticle suspension were determined by SALD2101. Suspension of silver nanoparticles became lyophilized powder by freeze-drying method and were kept in a closed container in the refrigerator at $4^{\circ} \mathrm{C}$ ( Guzmán et al., 2009).

\section{Evaluation of anti-planctonic effects of silver nanoparticles}

Antimicrobial effects of silver nanoparticles against the planctonic form were determined using Kirby-Bauer method in Muller-Hinton Agar (Merck, Germany). The lyophilized powder of silver nanoparticles was used for the preparation of discs with concentrations of $5,25,100$, and $400 \mu \mathrm{g} / \mathrm{disc}$. The petri dishes were evaluated after $24 \mathrm{~h}$ incubation at $37^{\circ} \mathrm{C}$ by measuring the inhibition diameter of growth around the disks.

The microdilution assay was also used to determine the MIC of silver nanoparticles against 10 planctonic form of each bacterium( Guzmán et al. 2009). First, serial dilutions of silver nanoparticles (4.6, 9.3, 18.7, 37.5, 75, 150, and $300 \mu \mathrm{g} / \mathrm{ml}$ ) were prepared. Then, the wells containing silver nanoparticles and Muller-Hinton Broth (Merck, Germany) were inoculated with the $10^{5} \mathrm{cfu} / \mathrm{m}$ tested strains and were incubated at $37^{\circ} \mathrm{C}$, and growth or no growth was evaluated after $24 \mathrm{~h}$. Additionally, the lowest concentration of nanoparticles that allows growth of less than $0.1 \%$ of the control culture is considered as minimal bactericidal concentration (MBC).

\section{Evaluation of biofilm inhibition activity of silver nanoparticles}

The microtitre assay was used to study the biofilm inhibition activity, and the second concentration of silver nanoparticles was used to obtain the biofilm inhibitory concentration (BIC). After preparing nanoparticles and inoculated $10^{5} \mathrm{cfu} / \mathrm{ml}$ bacteria, the micro-plates were incubated at $37^{\circ} \mathrm{C}$. The wells were washed with $200 \mu \mathrm{l}$ phosphate buffer saline two times after $48 \mathrm{~h}$. Then, $200 \mu \mathrm{l}$ of $0.1 \%$ crystal violet was added to the wells and incubated for 15 minutes; the wells were washed with water and allowed to dry at room temperature. Extra color attached to the surface was removed by ethanol $95 \%$; finally optic density (OD) of stained biofilms was read by ELISA auto-reader at wave length 570nm The percentage of biofilm inhibition was calculated by the following formula: $\{$ The percentage of biofilm inhibition $=($ OD Control - OD Treat $) /$ OD Control $\times$ $100\}$ (Namasivayam et al.,2012).

\section{Statical analysis}

In this study, all tests were repeated 3 times. Data was entered into the SPSS software version 16 and the results were analyzed by One-way ANOVA, LSD post hoc and Two-way correlated analysis of variance tests. In this study, Pv $\leq$ 0.05 was regarded statistically significant.

\section{RESULTS AND DISCUSSION}

\section{Biofilm detection}

Biofilms are communities of microbes that its function depends on a complex network of biological interactions ( $\mathbf{L i}$ and Tian, 2012). Microorganisms associated with biofilms behave differently in growth rates. In the present study, three methods were used for biofilm detection, and the MA assay was more sensitive than Congo red agar and tube methods. According to a previous study, the MA is a gold standard assay for biofilm detection (Mathur et al., 2006). The most common biofilm producing bacteria was $S$. aureus (Chart 1), and biofilmformation was different among the 3 bacteria $(\mathrm{Pv}=0.01)$. The biofilm formation probably is associated with type of clinical samples $(\mathrm{Pv}=0.05)$. All $S$. aureus producing biofilm were isolated from wound infections, $P$. aeruginosa producing biofilm were often isolated from urine and throat samples, and $E$.coli producing biofilm were isolated from urine samples.

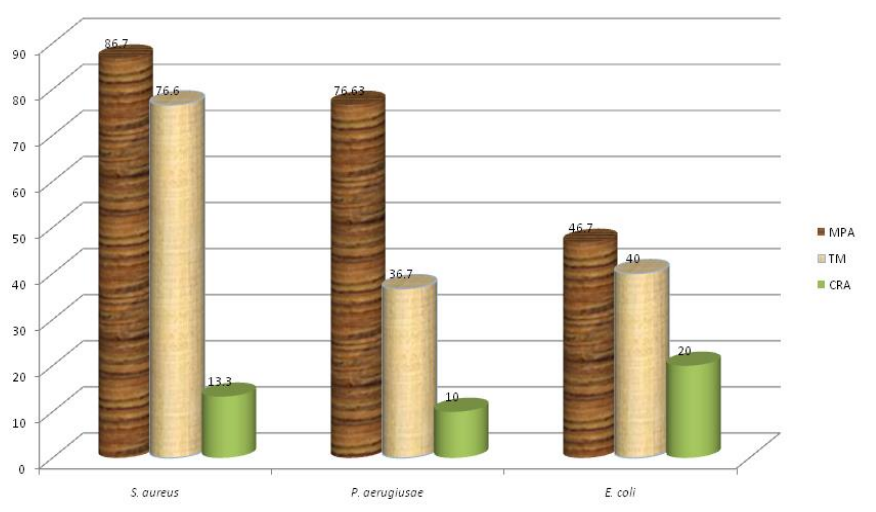

Chart 1 The frequency of biofilm-formation by MA, TM and CRA methods in tested bacteria

\section{Evaluation of anti-planctonic effects of silver nanoparticles}

Antimicrobial effects of silver nanoparticles were tested by disk diffusion agar and microdilution methods, and according to the disk diffusion agar results, increasing the concentration of nanoparticles in the discs will be increase the diameter of the inhibition zone (Table 1). Additionally, the post hoc LSD tes confirmed this result. Based on the diameter of the growth inhibitory, $P$ aeruginosa isolates showed more sensitivity to nanoparticles in comparison to $S$ aureus isolates and is also more sensitive than E. coli isolates.

Table 1The antimicrobial effects of silver nanoparticles against planctonic form by disk diffusion agar method.

\begin{tabular}{lcccc}
\hline & $\mathbf{4 0 0} \boldsymbol{\mu g} / \mathbf{d i s c}$ & $\mathbf{1 0 0} \boldsymbol{\mu g} / \mathbf{d i s c}$ & $\mathbf{2 5} \boldsymbol{\mu g} / \mathbf{d i s c}$ & $\mathbf{5 \mu g} / \mathbf{d i s c}$ \\
\hline S. aureus & $14.2^{*}$ & 12.4 & 6.9 & 6 \\
E. coli & 11.6 & 9.8 & 6.5 & 6 \\
P. aeruginosa & 16.6 & 13.6 & 10.11 & 7.9 \\
\hline * The mean growth inhibition size (millimeter) of bacteria with different concentration of
\end{tabular}
silver nanoparticles.

The MIC and MBC results of silver nanoparticles against bacteria are shown in Table 2. One-way ANOVA test showed that the MIC and MBC of nanoparticles were significantly different in various bacteria. The effects of silver nanoparticles against $E$. coli was less than $S$. aureus and $P$. aeruginosa. According to the results of the post hoc LSD test, there are significant differences between isolates of $S$. aureus and P. aeruginosa and E. coli in terms of MIC and $\mathrm{MBC}(\mathrm{Pv}=0.05$, but there were no significant differences between isolates of $S$. aureus and $P$. aeruginosa $(\mathrm{Pv}=0.741)$. In this study, based on the results of MIC values, silver nanoparticles had almost the same effect on Gram-positive bacteria ( $S$. aureus) and Gram-negative bacteria ( $P$. aeruginosa), whilst MIC in $70 \%$ of E. coli was doubled in comparison to $S$. aureus and $P$. aeruginosa. There are controversy about the effects of silver nanoparticles on Gram-positive bacteria and Gramnegative bacteria. Shrivastava et al. (2007) reported that silver nanoparticles are generally more active on Gram-negative bacteria than Gram-positive bacteria The resistance of Gram postive bacteria to silver nanoparticles may be due to the cell wall and the thick peptidoglycan layer of Gram-positive bacteria (Feng $\boldsymbol{e}$ al., 2001). Similar to our data, Doudi et al. (2011) and Ruparelia et al. (2008) reported that $E$. coli had a higher resistance to silver nanoparticles than $S$. aureus. Some researcher believe that lipopolysaccharide of Gram-negative bacteria trap positively charged silver nanoparticles and lead to the blocking of nanoparticles. As a result, antibacterial activity of silver nanoparticles needs to reach the cell membrane. In fact, the silver nanoparticles are attached to the surface of cell membranes and can disrupted the performance of the membrane, penetrate the cell and release silver ions.

Table 2 The MIC and MBC results of silver nanoparticles against 10 planctonic form of each bacterium

\begin{tabular}{lccc}
\hline & Number $(\%)$ & MIC $(\boldsymbol{\mu g} / \mathbf{m L})$ & MBC $(\boldsymbol{\mu g} / \mathbf{m L})$ \\
\hline S. aureus & $8(80)$ & 75 & 150 \\
& $2(20)$ & 37.5 & 75 \\
\multirow{2}{*}{ E. coli } & $6(60)$ & & \\
& $4(40)$ & 750 & 300 \\
P. aeruginosa & $9(90)$ & 75 & 150 \\
& $1(10)$ & 37.5 & 150 \\
\hline
\end{tabular}

\section{Evaluation of biofilm inhibition activity of silver nanoparticles}

The average percentage of biofilm inhibition in $S$. aureus, $P$. aeruginosa and $E$. coli isolates by silver nanoparticles at a second concentrations were $58 \%, 56 \%$ and $44 \%$, respectively. However, the potency of silver nanoparticle biofilm 
inhibition was different and the percentage of biofilm inhibition by silver nanoparticles in $E$. coli was less than $P$. aeruginosa and $S$. aureus. Two-way correlated analysis of variance results showed that silver nanoparticles were effective against bacterial biofilm $(\mathrm{Pv}=0.01)$. The amount of biofilm inhibition is significantly different between diverse doses of silver nanoparticles. Statistical analysis post hoc LSD tests showed that the percentage of biofilm inhibition at high doses was more than low doses.

In general, the ability of resistance to antimicrobial agents in biofilm is 10 to 1000 times higher than planctonic cells (Czaczyk and Myszka, 2007; Taylor and Webster, 2009; Monroe, 2007). In this study, silver nanoparticles had potent anti-biofilm effects. Antimicrobial effects of silver nanoparticles have been previously studied (Taylor and Webster, 2009; Li and Tian, 2012; Velázquez-Velázquez et al., 2015), but there are a few studies on effects of silver nanoparticles against bacterial biofilm (Guzmán et al., 2009; Mathur et al.,2006). A study from India reported that the production of biofilms in E. coli, S. aureus, Salmonella typhi and Vibrio cholerae were inhibited by silver nanoparticles (Kumar et al., 2012). Namasivayam et al. (2012) studied the effects of alone silver nanoparticles and also in combination with several antibiotics, and they concluded that silver nanoparticles made a complete inhibition of biofilm within 24 hours, as well as a good compatibility with combination of silver nanoparticles and antibiotics to inhibit biofilm.

The range of silver nanoparticles size was 50 to $150 \mathrm{~nm}$ and average particle size was $92 \mathrm{~nm}$ (Chart 2). The high surface to volume ratio of nanoparticles plays an important role in inhibiting the growth of bacteria. Our study showed that bactericidal effects of nanoparticles is influenced by the particle diameter Therefore, the choice of synthesis method is effective for controlling the size of silver nanoparticles (Guzmán et al., 2009). The small particles were more antibacterial and had more antibiofilm activity than large particles, as well as, the triangular-shaped nanoparticles antimicrobial activity was more than spherica particles. In the past studies it was also reported that antimicrobial activity depends on the size of the nanoparticles (Martinez-Castanon et al 2008; Pal et al., 2007).

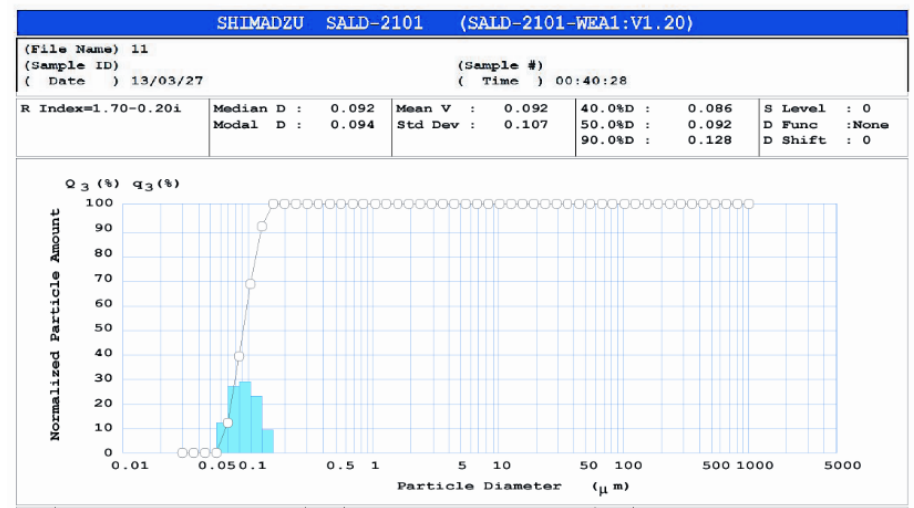

Chart 2 The range of silver nanoparticles size

\section{CONCLUSION}

The biofilm formation is associated with type of clinical specimens. The small particles of silver nanoparticles are more antibiofilm activity, and antibacterial activity depends on concentration. This research shows that silver nanoparticles have strong antibacterial and antibiofilm activity. The antibiofilm effectes of silver nanoparticles against bacteria is different and $P$. aeruginosa isolates is more sensitive to nanoparticles. The silver nanoparticles can be used to inhibit bacterial biofilms, and may be useful for treatment of infectious diseases due to biofilm. We recommend conducting more studies concerning this issue and particularly conducting in vivo and clinical trial searches before the administration of silver nanoparticles in the treatment of infections due to biofilms.

Acknowledgments: This article is based on data from an M. Sc thesis. The authors are grateful to Dr. H. Bannazadeh Baghii for English language editorial assistance.

\section{REFERENCES}

Czaczyk, K., \& Myszka, K. (2007). Mechanisms determining bacterial biofilm resistance to antimicrobial factors. Biotechnologia, 76(1), 40-52. http://dx.doi.org/10.5772/33048

Doudi, M., Karami, M., \& Amirmozafari, N. (2011). Bacterial effect of silver nanoparticles against multidrug-resistant bacteria. Clin. Biochem., 44(13), S223. http://dx.doi.org/10.1016/j.clinbiochem.2011.08.984

Dunn, K., \& Edwards-Jones, V. (2004). The role of Acticoat ${ }^{\mathrm{TM}}$ with nanocrystalline silver in the management of burns. Burns, 30, S1-S9. http://dx.doi.org/10.1016/s0305-4179(04)90000-9
Feng, Q., Wu, J., Chen, G., Cui, F., Kim, T., \& Kim, J. (2001). A mechanistic study of the antibacterial effect of silver ions on Escherichia coli and Staphylococcus aureus. J. Biomed. Mater. Res.(52), 662-668 http://dx.doi.org/10.1002/1097-4636(20001215)52:4<662::aid-jbm10>3.0.co;2-3 Guzmán, M. G., Dille, J., \& Godet, S. (2009). Synthesis of silver nanoparticles by chemical reduction method and their antibacterial activity. Int J Chem Biomol Eng, 2(3), 104-111.

Hassan, A., Usman, J., Kaleem, F., Omair, M., Khalid, A., \& Iqbal, M. (2011) Evaluation of different detection methods of biofilm formation in the clinica isolates. Braz J Infect Dis, 15(4), 305-311. http://dx.doi.org/10.1590/s1413 $\underline{86702011000400002}$

Høiby, N., Bjarnsholt, T., Moser, C., Bassi, G. L., Coenye, T., Donelli, G., ... \& Lebeaux, D. (2015). ESCMID guideline for the diagnosis and treatment of biofilm infections 2014. Clinical Microbiology and Infection, 21, S1-S25.

Joseph, R. (2003). Prosthetic joint infections: Bane of orthopedists. Clin. Infect. Dis., 36, 1157-1161. http://dx.doi.org/10.1086/374554

Kim, J. S., Kuk, E., Yu, K. N., Kim, J.-H., Park, S. J., Lee, H. J., . . . Hwang, C.Y. (2007). Antimicrobial effects of silver nanoparticles. Nanomedicine, 3(1), 95 101

Kumar, P., Senthamilselvi, S., Lakshmipraba, A., Premkumar, K., Muthukumaran, R., Visvanathan, P., . . Govindaraju, M. (2012). Efficacy of biosynthsized silver nanoparticles using acanthophora spicifera to encumber biofilm formation. Dig J Nanomater Biostruct, 7(2), 511-522.

Lellouche, J., Friedman, A., Lellouche, J.-P., Gedanken, A., \& Banin, E. (2012) Improved antibacterial and antibiofilm activity of magnesium fluoride nanoparticles obtained by water-based ultrasound chemistry. Nanomedicine, 8(5), 702-711. doi: 10.1016/j.nano.2011.09.002

Li, Y.-H., \& Tian, X. (2012). Quorum sensing and bacterial social interactions in biofilms. Sensors, 12(3), 2519-2538. http://dx.doi.org/10.3390/s120302519

Mah, T.-F. C., \& O'Toole, G. A. (2001). Mechanisms of biofilm resistance to $\begin{array}{llll}\text { antimicrobial agents. Trends } & \text { Microbiol., } & 9(1), & 34-39 .\end{array}$ http://dx.doi.org/10.1016/s0966-842x(00)01913-2

Mahon, C. R., Lehman, D. C., \& Manuselis Jr, G. (2014). Textbook of diagnostic microbiology. Elsevier Health Sciences.

Martinez-Castanon, G., Nino-Martinez, N., Martinez-Gutierrez, F., MartinezMendoza, J., \& Ruiz, F. (2008). Synthesis and antibacterial activity of silver nanoparticles with different sizes. J Nanopart Res, 10(8), 1343-1348. http://dx.doi.org/10.1007/s11051-008-9428-6

Mathur, T., Singhal, S., Khan, S., Upadhyay, D., Fatma, T., \& Rattan, A. (2006) Detection of biofilm formation among the clinical isolates of staphylococci: an evaluation of three different screening methods. Indian J Med Microbiol, 24(1), 25. http://dx.doi.org/10.4103/0255-0857.19890

Monroe, D. (2007). Looking for chinks in the armor of bacterial biofilms. PLoS Biol., 5(11), e307. http://dx.doi.org/10.1371/journal.pbio.0050307

Namasivayam, S. K. R., Preethi, M., Bharani, A., Robin, G., \& Latha, B. (2012) Biofilm inhibitory effect of silver nanoparticles coated catheter agains Staphylococcus aureus and evaluation of its synergistic effects with antibiotics. Int J Biol Pharm Res, 3, 259-265.

Odeyemi, O.A., Asmat, A., Usup, G. (2012). Antibiotics resistance and putative virulence factors of Aeromonas hydrophyla isolated from Estuary. JMBFS. 1 (6), 1339-1357.

Pal, S., Tak, Y. K., \& Song, J. M. (2007). Does the antibacterial activity of silver nanoparticles depend on the shape of the nanoparticle? A study of the gramnegative bacterium Escherichia coli. Appl. Environ. Microbiol., 73(6), 1712 1720. http://dx.doi.org/10.1128/aem.02218-06

Ravishankar Rai, V., \& Jamuna Bai, A. (2011). Nanoparticles and their potential application as antimicrobials. Science against microbial pathogens. communicating current research and technological advances. FORMATEX, $197-$ 209.

Ruparelia, J. P., Chatterjee, A. K., Duttagupta, S. P., \& Mukherji, S. (2008) Strain specificity in antimicrobial activity of silver and copper nanoparticles Acta Biomater, 4(3), 707-716. http://dx.doi.org/10.1016/i.actbio.2007.11.006

Samia, A., Dayal, S., \& Burda, C. (2006). Quantum Dot-based energy transfer: perspectives and potential for applications in photodynamic therapy. Photochem Photobiol., 82(3), 617-625. http://dx.doi.org/10.1562/2005-05-11-ir-525

Shrivastava, S., Bera, T., Roy, A., Singh, G., Ramachandrarao, P., \& Dash, D (2007). Characterization of enhanced antibacterial effects of novel silve nanoparticles. Nanotechnology, 18(22), 225103. http://dx.doi.org/10.1088/09574484/18/22/225103

Southey-Pillig, C. J., Davies, D. G., \& Sauer, K. (2005). Characterization of temporal protein production in Pseudomonas aeruginosa biofilms. J. Bacteriol. 187(23), 8114-8126. http://dx.doi.org/10.1128/jb.187.23.8114-8126.2005

Taylor, E. N., \& Webster, T. J. (2009). The use of superparamagnetic nanoparticles for prosthetic biofilm prevention. Int J Nanomedicine, 4, 145 http://dx.doi.org/10.2147/ijn.s5976

Velázquez-Velázquez, J. L., Santos-Flores, A., Araujo-Meléndez, J., SánchezSánchez, R., Velasquillo, C., González, C., ... \& Martinez-Gutierrez, F. (2015) Anti-biofilm and cytotoxicity activity of impregnated dressings with silver nanoparticles. Materials Science and Engineering: C, 49, 604-611. 
Whitesides, G. M. (2003). The'right'size in nanobiotechnology. Nat. Biotechnol., 21(10), 1161-1165. 